\title{
The Development of Inflatable Array Antennas
}

\author{
UDK 621.396.67 \\ IFAC IA 5.8 .3
}

\begin{abstract}
Inflatable array antennas are being developed to significantly reduce the mass, the launch vehicle's stowage volume, and the cost of future spacecraft systems. Three inflatable array antennas, recently developed for spacecraft applications, are a $3.3 \mathrm{~m} \times 1.0 \mathrm{~m} \mathrm{~L}$-band synthetic aperture radar (SAR) array, a $1.0 \mathrm{~m}$-diameter X-band telecom reflectarray, and a $3 \mathrm{~m}$-diameter Ka-band telecom reflectarray. All three antennas are similar in construction, and each consists of an inflatable tubular frame that supports and tensions a multi-layer thin-membrane radiating surface with printed microstrip patches. These antennas demonstrated that inflatable arrays are feasible across the microwave and millimeter-wave spectrums. Further developments of these antennas are deemed necessary, in particular, in the area of qualifying the inflatable structures for space-environment usage.
\end{abstract}

Key words: antennas, inflatable structure, planar arrays, reflectarray, spacecraft

\section{INTRODUCTION}

JPL/NASA's Earth remote sensing and deep-space exploration programs have increasing demand for spacecraft high-gain and large aperture antennas. At the same time, however, low mass and small stowage volume are emphasized on these antennas in order to reduce payload weight and size and thus reduce launch cost. To meet these goals, large-aperture antennas must be deployable. One deployable concept using an inflatable parabolic reflector [1] was introduced about two decades ago and was demonstrated in a recent space shuttle experiment [2]. However, the full implementation of this concept is still hampered by the inability to achieve and maintain the required surface accuracy. Even with a rigidizable membrane and an inflatable support structure, it is believed that it will be difficult to maintain the desired surface accuracy of a large parabolic aperture for the duration of a long space flight. To mitigate the difficulty associated with curved surfaces, a new class of planar array technology is being developed [3, 4]. It is believed that it will be significantly simpler to maintain the required surface tolerance of a flat »natural« surface, such as a planar array, than a curved »non-natural « surface, such as a parabolic reflector. In addition, a planar array offers the possibility of wide-angle beam scanning, which cannot be easily achieved by a parabolic reflector.

At JPL, three inflatable planar array antennas have recently been developed [5]. Most of the RF capabilities and a portion of the mechanical capabilities of these antennas have been demonstrated for space application. These three antennas are the $3.3 \mathrm{~m} \times 1.0 \mathrm{~m}$ L-band SAR array for Earth remote sensing application, the $1.0 \mathrm{~m}$-diamater $\mathrm{X}$-band reflectarray and the $3 \mathrm{~m}$-diameter Ka-band reflectarray for deep-space telecom application. The RF design and the aperture membrane surface of these antennas were developed at JPL, while the development of the inflatable structures and the antenna integration were accomplished by ILC Dover, Inc. and L'Garde Corp. These antennas demonstrated that inflatable arrays are feasible across the microwave and millimeter-wave spectrums. Further developments of these antennas are deemed necessary, in particular, in the area of qualifying the inflatable structures for space environment usage.

\section{ANTENNA DESCRIPTION AND PERFORMANCE}

All three inflatable antennas are constructed and deployed in a similar fashion. Each antenna is basically constructed from an inflatable tubular frame that supports and tensions a multi-layer thin-membrane RF radiating surface with many printed microstrip patch elements. All three antennas are deployed by a »roll out « mechanism as a carpet is rolled out. The folding mechanism is not used here to avoid forming large creases on the printed patch elements and transmission lines. Any large crease may significantly degrade the RF performance. All three antennas were developed as breadboards for the purpose of initial technology demonstration to assure that the inflated thin membrane can indeed yield proper RF performance. Several technologies remain to be developed in the future to allow these 
antennas to be used in the space environment. The detailed description and performance of these antennas are separately presented in the following subsections.

\section{L-Band SAR Array:}

Antenna Description - The inflatable L-band SAR array, having an aperture size of $3.3 \mathrm{~m} \times 1.0 \mathrm{~m}$, is a technology demonstration model with $1 / 3$ the size of the future full size $(10 \mathrm{~m} \times 3 \mathrm{~m})$ array. Two such inflatable arrays were recently developed: one by ILC Dover, Inc. and the other by L'Garde Corp. Both antennas' concepts and electrical designs were accomplished at JPL, while the inflatable structures were developed by the two companies. The ILC Dover unit is shown in Figure 1, and the L'Garde unit is given in Figure 2. Both units are very similar and each basically is a rectangular frame of inflatable tubes that support and tension a three-layer thin-membrane radiating surface with microstrip patches and transmission lines as shown in Figure 3. The top layer has all the rectangular patches with a set of microstrip power divider lines for generating horizontal polarization. The middle layer is the ground plane with a set of aperture coupling slots. The bottom layer has only the power divider lines that excite the top-layer patches with vertical polarization through the coupling slots in the ground plane layer. The inflatable tube of the ILC Dover unit has a diameter of $13 \mathrm{~cm}$ and is made of 0.25 mm-thick urethane coated Kevlar material. The L'Garde's inflatable tube has a diameter of $9 \mathrm{~cm}$ and is made of $0.08 \mathrm{~mm}$-thick rigidizable stretched aluminum material. The rigidizable tube is used to avoid the need of constant air pressure and the concern of air leakage due to space debris damage. The three membrane layers are separated $1.27 \mathrm{~cm}$ between the top radiator layer and the middle

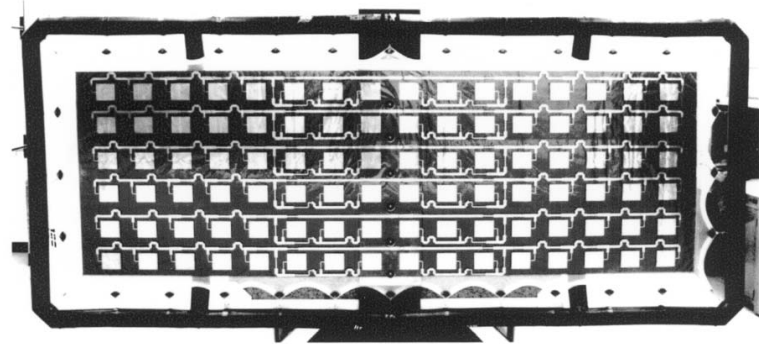

Fig. 1 Inflatable L-band SAR array developed by JPL/ILC Dover Inc.

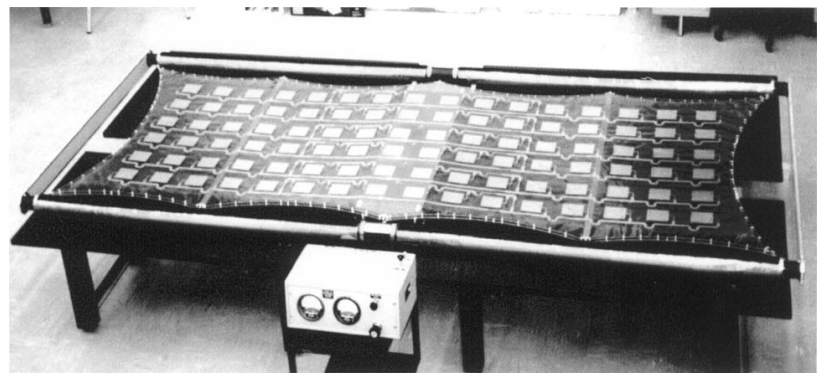

Fig. 2 Inflatable L-band SAR array developed by JPL/L'Garde Corp.

ground-plane layer and $0.635 \mathrm{~cm}$ between the middle layer and the bottom transmission-line layer. The connection between these membranes and the inflated tubular frame is made by a series of catenary attachment points and tension cords. The required spacings between the three membranes are maintained by the tension of the catenary cords, the honeycomb spacing panels and bars, and small spacing blocks at each of the catenary points. The membrane material used is a thin film of 5-micron-thick copper cladding on a 0.13 -mm-thick Kapton dielectric material.
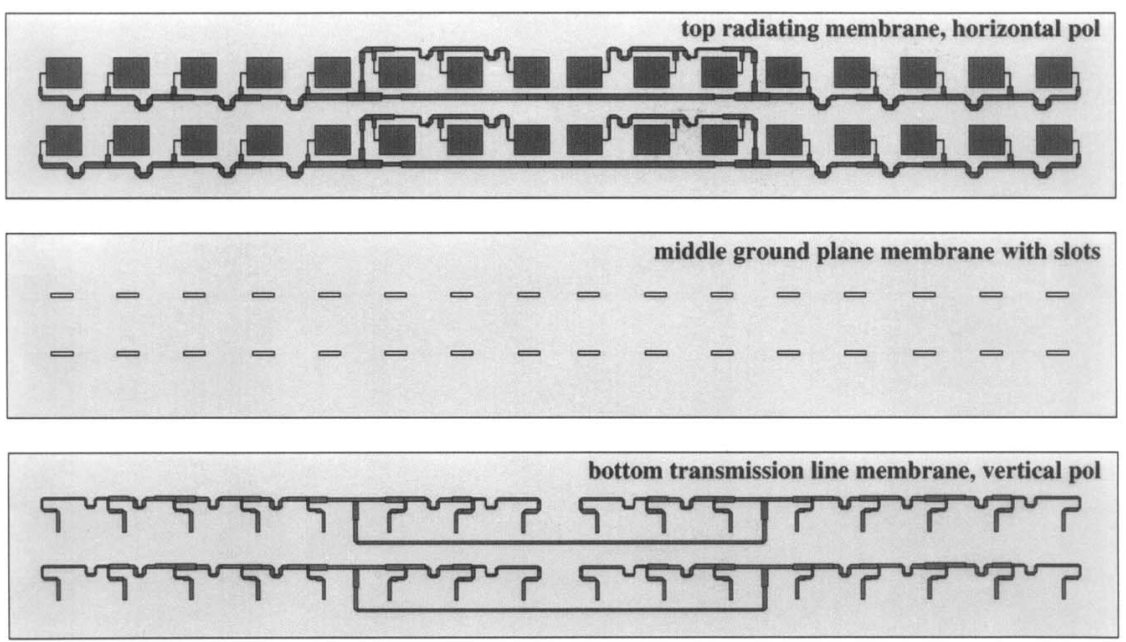

Fig. 3 Three membranes showing dual-polarized microstrip array 
Antenna test results - The L'Garde unit achieved a total antenna mass of $11 \mathrm{~kg}$ with an average mass density of $3.3 \mathrm{~kg} / \mathrm{m}^{2}$. The ILC Dover unit has a slightly higher mass. The surface flatness of the L'Garde unit was measured to be $\pm 0.28 \mathrm{~mm}$ and is better than the requirement of $\pm 0.8 \mathrm{~mm}$. The ILC Dover's surface flatness was measured to be \pm 0.7 $\mathrm{mm}$. Both antenna units achieved bandwidths slightly wider than the required $80 \mathrm{MHz}$, and achieved port isolation between the two orthogonal polarizations of greater than $40 \mathrm{~dB}$ within the required bandwidth. The radiation patterns of both the ILC Dover and the L'Garde units were measured at JPL's 300-meter outdoor far-field range. The illuminating and the test antennas were mounted on two hill tops with a deep canyon between the two antennas to avoid ground multi-path reflections. Each inflatable antenna was mounted on a rigid support frame, which was then mounted on a 3-axes rotatable pedestal system. The patterns were taken between $7 \mathrm{pm}$ and $1 \mathrm{am}$ in the evening when the local wind speed is at a minimum. It was noticed that a slight surface distortion or vibration due to a light breeze at the L-band frequency did not produce significant pattern effect. As a typical example, the pattern of the ILC Dover unit measured in one principal plane at $1.25 \mathrm{GHz}$ is given in Figure 4.

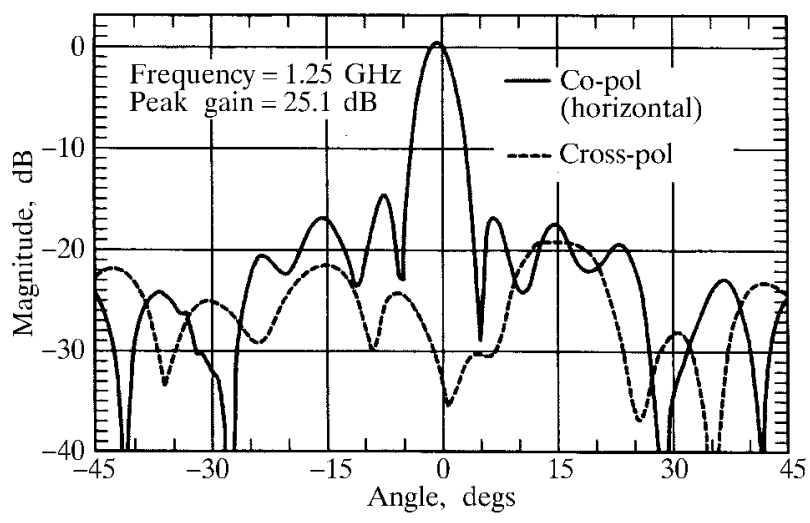

Fig. 4 Measured pattern of the inflatable SAR array along the aperture's long dimension

Sidelobe levels of $-14 \mathrm{~dB}$ in this plane is very reasonable for this uniformly distributed array. The cross-pol level of less than $-20 \mathrm{~dB}$ within the main beam region is also considered acceptable for this radar application. Pattern measured at frequencies from $1.21 \mathrm{GHz}$ to $1.29 \mathrm{GHz}$ are very similar to those shown in Figure 4 without significant degradation.

The measured peak gain of ILC Dover's unit is $25.2 \mathrm{~dB}$ at $1.25 \mathrm{GHz}$, which corresponds to an aperture efficiency of $52 \%$. L'Garde's unit has a peak gain of $26.7 \mathrm{~dB}$ and an aperture efficiency of $74 \%$.
The better efficiency of L'Garde's unit is the result of better surface tolerance and more precise membrane spacing. Nevertheless, both units are considered quite good as they are the first demonstration models ever developed.

\section{X-Band 1-m Reflectarray:}

Antenna description - The inflatable X-band reflectarray antenna [6], shown in Figure 5, has an inflated torus tube that supports and tensions the one-meter-diameter two-layer-membrane reflectarray surface. The antenna's overall RF system and the aperture membrane surface were designed at JPL, while the inflatable structure and antenna integration were developed by ILC Dover, Inc. The inflated tripod tubes are attached to the torus as struts to support a feed horn. The inflatable tubes are made of $0.25 \mathrm{~mm}$-thick urethane coated Kevlar material and the reflectarray membrane material is made of 5-micron-thick copper cladding on 0.05 mm-thick Kapton. There are a total of two membrane layers separated by $1.3 \mathrm{~mm}$. The top copper layer was etched to produce approximately 1,000 isolated microstrip patches, while the un-etched bottom layer serves as the ground plane. Many small precision foam discs ( $7 \mathrm{~mm}$ diameter) were placed between the two membranes as means of maintaining the required uniform membrane spacing.

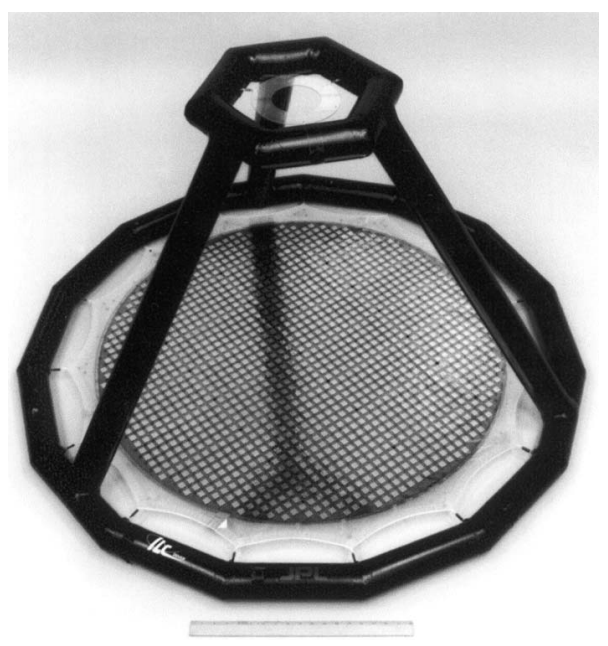

Fig. 5 One-meter X-band inflatable reflectarray

Antenna test results - This inflatable antenna structure achieved a mass of $1.2 \mathrm{~kg}$, which excludes the mass of the inflatant system and the feed horn. With future development, it is believed that the mass of the inflatant system (possibly using solid inflatant) for this particular antenna size can be on the order of $0.5 \mathrm{~kg}$. The microstrip patches on the top layer membrane are all square in shape and 


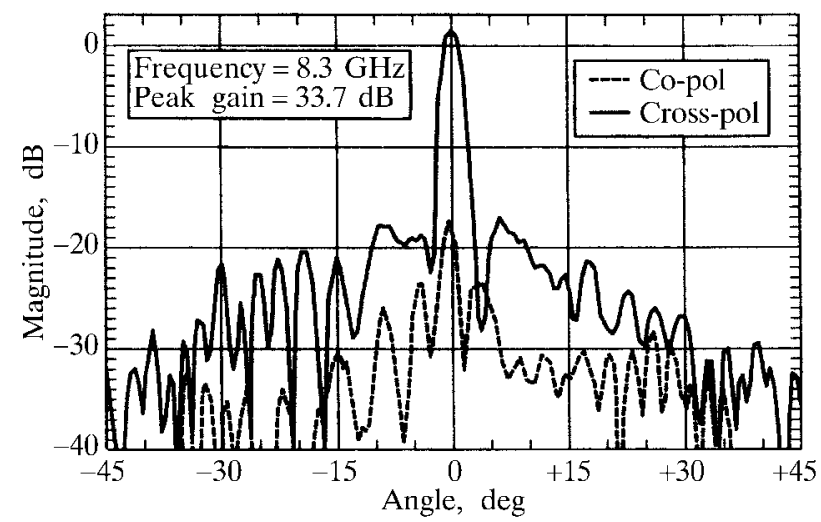

Fig. 6 Measured radiation pattern of the 1-m X-band inflatable reflectarray

identical in size, but with different-length phase-delay lines attached. These phase-delay lines are used to compensate for the differential phases of the different path lengths from the feed horn to all the patches. Each patch has two equal-length phase-delay lines orthogonally attached. With the feed horn left-hand circularly polarized, the re-radiated fields from the patches are remain left-hand circularly polarized. The antenna patterns were tested at the JPL's 300-meter outdoor far-field range in a similar fashion as that mentioned before for the L-band inflatable SAR antennas. A typical measured elevation pattern at $8.3 \mathrm{GHz}$ is given in Figure 6 where the peak sidelobe level $(-19 \mathrm{~dB})$ and peak cross-pol level $(-19 \mathrm{~dB})$ are both acceptable to the communication system. However, the peak sidelobe of $-19 \mathrm{~dB}$ is higher than the expected $-25 \mathrm{~dB}$. This is primarily due to the blockage effects of the feed and feed support struts. The main beam of the antenna has a $-3 \mathrm{~dB}$ beamwidth of 2.4 which is expected from an $\mathrm{X}$-band circular aperture of $1 \mathrm{~m}$ diameter. The antenna also achieved the expected $-1 \mathrm{~dB}$ gain-bandwidth of $250 \mathrm{MHz}$ (about $3 \%$ ). The measured peak gain at $8.3 \mathrm{GHz}$ is $33.7 \mathrm{dBi}$ which implies an antenna efficiency of $37 \%$. The expected efficiency from an X-band $1 \mathrm{~m}$ aperture should be about $50 \%$. The relatively poor efficiency achieved by this inflatable reflectarray is primarily due to design and manufacturing inexperience in building this first demonstration model. Imperfect separation between membranes, feed and strut blockage, surface roughness, leakage radiation from phase delay lines are all contributors to the inefficiency. All these errors are believed to be correctable for future models.

\section{Ka-Band 3-m Reflectarray:}

Antenna description - A photograph of the inflatable Ka-band reflectarray antenna with a 3-m-diameter aperture is shown in Figure 7. This antenna, similar to the above X-band reflectarray, was co-de-

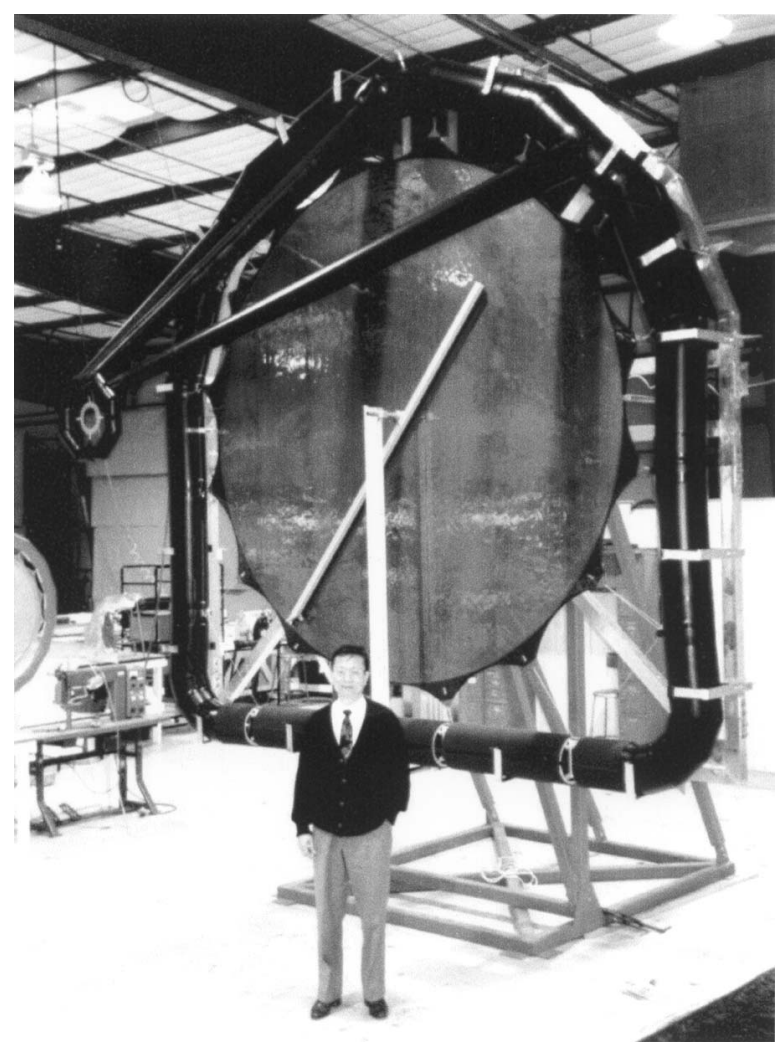

Fig. 7 Three-meter Ka-band inflatable reflectarray

veloped by JPL and ILC Dover, Inc. It consists of a horse-shoe shaped inflatable tube that supports and tensions the 3-m aperture membrane. The tube, $25 \mathrm{~cm}$ in diameter, is made of urethane coated Kevlar and is inflated to 3.0 psi pressure, which translates to about $90 \mathrm{psi}$ of tension force to the aperture membrane. The inflatable tube is connected to the aperture membrane at 16 catenary points with spring-loaded tension cords. Each connecting point has displacement adjustment capability in the $x, y, z$ directions so that the circumference of the circular aperture membrane can be made into a single plane orthogonal to the feed horn axis. The single-layer aperture membrane is a 5 -mil $(0.13 \mathrm{~mm})$ thick Uplex $^{\mathrm{TM}}$ dielectric material (a brand of polyimide) with both sides clad with 5-micron thick copper. The copper on one side was etched to form approximately 200,000 microstrip patch elements while the copper on the other side is un-etched and serves as the ground plane for the patch elements. The inflatable tripod tubes, asymmetrically located on the top portion of the horse-shoe structure, are used to support a Ka-band corrugated feed horn. The horse-shoe-shaped main tube structure and the asymmetrically connected tripod tubes are uniquely designed in geometry to avoid membrane damage and flatness deviation when the deflated antenna structure is rolled up. 


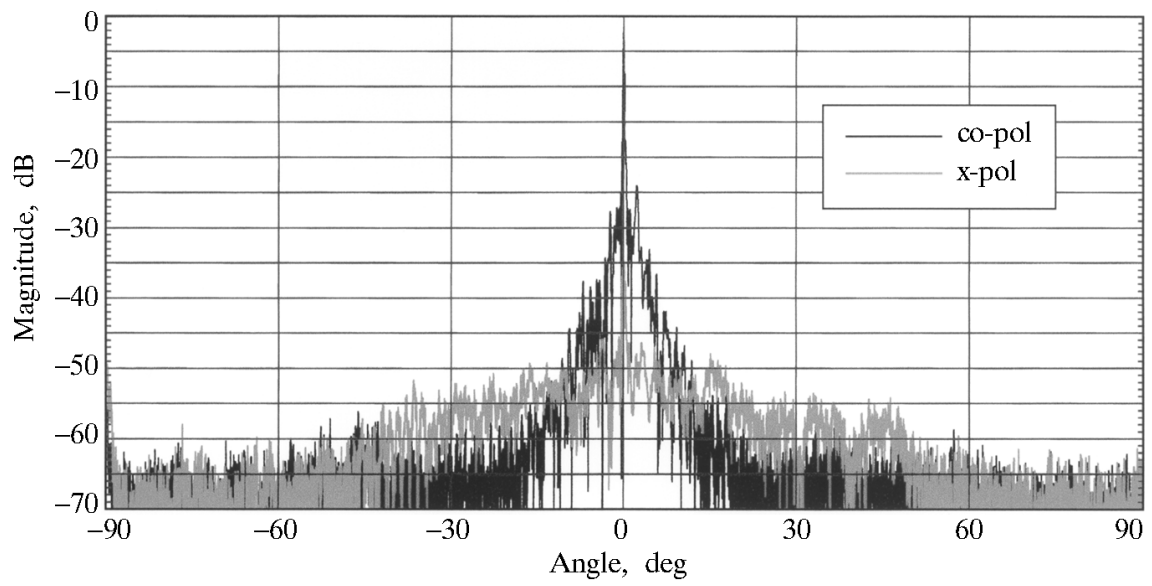

Fig. 8 Measured radiation pattern of the $3 \mathrm{~m}$ Ka-band inflatable reflectarray

Antenna test results - Due to the requirement of maintaining an extremely tight surface tolerance (0.5 mm RMS) during antenna pattern measurement, the antenna's RF tests were performed at the in-door compact range of Composite Optics, Inc. (COI), where up-to-10 m size antenna can be tested. This compact range has a huge parabolic reflector (22-m maximum dimension) that transmits field, close to its aperture, with a planar phase front to simulate far-field illumination. During the test, the inflatable antenna was mounted in a rigid frame structure as that shown in Figure 7. A typical elevation pattern of the antenna is given in Figure 8 where a 0.22 beamwidth was measured. The sidelobe level is $-30 \mathrm{~dB}$ or lower below the main beam peak, and the cross-pol level is $-40 \mathrm{~dB}$ or lower. All patch elements are circularly polarized and are identical in dimensions. Their angular rotations are different [7] and are designed to provide correct

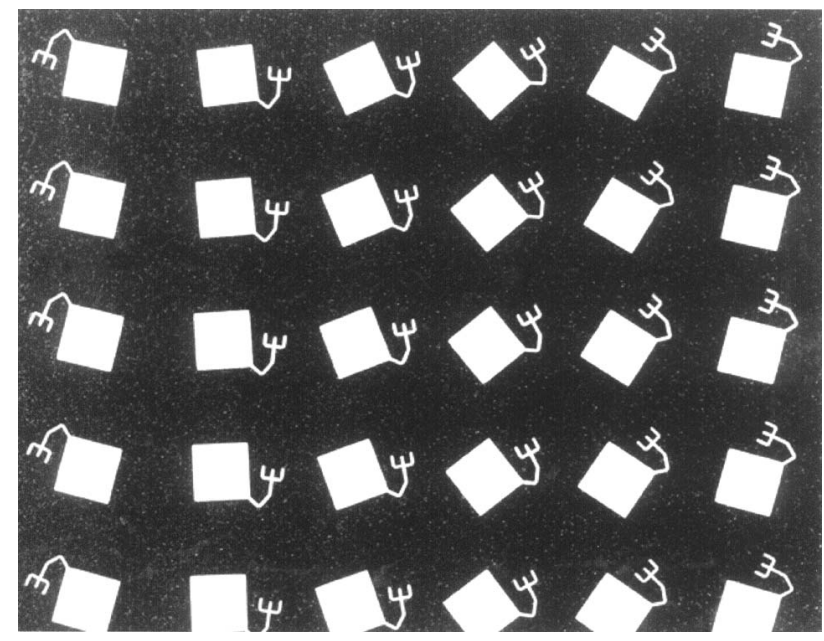

Fig. 9 Variably rotated patch elements of the $3 \mathrm{~m}$ inflatable reflectarray phase delays to achieve a co-phasal aperture distribution. A close-up view of a small portion of the elements is given in Figure 9. Each element is a slightly rectangular patch with phase delay line placed at its corner for left-hand circular polarization application. The fork-look-alike structure at the end of the phase delay line is for impedance matching purpose. The antenna gain was measured versus frequency. The results show that the antenna is tuned at the desired frequency of $32.0 \mathrm{GHz}$ with a $-3 \mathrm{~dB}$ bandwidth of $550 \mathrm{MHz}$. A peak gain of $54.4 \mathrm{dBic}$ was measured. This measured antenna gain indicates an aperture efficiency of $30 \%$, which is away from the expected $40 \%$. This relatively lower efficiency was the result of poor focal point alignment, large feed struts blockage, and high loss-tangent substrate material (loss-tangent is 0.008 at Ka-band). The phase delay line that attached to each patch element has certain amount of impedance mis-match to the patch and, thus, sending some amount of RF power to form undesirable cross-pol energy and resulting in poor radiation efficiency. It is quite certain that future development can improve the efficiency to the expected $40 \%$ or higher. The measured surface flatness data of the antenna aperture shows a RMS value of $0.2 \mathrm{~mm}$, while the required surface RMS value is $0.5 \mathrm{~mm}$. This good surface flatness is also reflected by the well-formed far-field pattern with expected main beamwidth and low sidelobe level. Although the aperture efficiency was not as expected, the achievement of excellent membrane flatness indicates that inflatable array antenna at Ka-band is now feasible.

\section{FUTURE CHALLENGES}

The basic structure of an inflatable array is a multilayer planar aperture surface that is supported 
and tensioned, through a catenary system, by several inflated tubular elements. In order to successfully develop an inflatable array antenna at any frequency throughout the microwave and millimeter-wave spectrums and with any aperture size from a few meters to tens of meters, several technical challenges must be addressed and resolved. These challenges are briefly listed below.

- Membrane flatness and separation

- Tube rigidization technique

- Controlled deployment

- Packaging efficiency

- Membrane mountable T/R modules

- Development of space survivable materials

- Mathematical modeling and simulation of static and dynamic space environmental effects.

\section{CONCLUSION}

Three inflatable array antennas have been developed at the microwave frequencies of L-band and $\mathrm{X}$-band, as well as at the millimeter-wave frequency of Ka-band. These antennas were developed to demonstrate that the inflatable array technology is feasible in reducing the mass and stowage volume of future spacecraft's high-gain and large-aperture antennas. To realize the inflatable array technology for space application, several challenges in the mechanical area remain to be resolved. The development of inflatable structure rigidization methods, controlled deployment techniques, space survivable membrane materials, and accurate mathematical structure analysis tools are necessary if successful space application is to be achieved.

\section{ACKNOWLEDGEMENT}

The authors are grateful to L'Garde Corp., ILC Dover, Inc., and Drs. Michael Lou and Alfonso Feria of JPL for their contribution to the development of the inflatable structures. The research described in this paper was carried out by the Jet Propulsion Laboratory, California Institute of Technology, under contract with the National Aeronautics and Space Administration.

\section{REFERENCES}

[1] M. Thomas, G. Veal, Highly Accurate Inflatable Reflectors. Report AFRPLTR84-023, May 1984.

[2] R. E. Freeland, G. D. Bilyeu, G. R. Veal, Large Inflatable Deployable Antenna Flight Experiment Results. IAF paper 97-1.3.01, $48^{\text {th }}$ Congress of the International Astronautical Federation, Turin, Italy, October 1997.

[3] J. Huang, M. Lou, E. Caro, Super-Low-Mass Spaceborne SAR Array Concepts. IEEE AP-S/URSI Symp. Digest, pp. 1288-1291, July 1997.

[4] J. Huang, Emerging Array Antenna Technologies at JPL. ANTEM Symp. Ottawa, Canada, Aug. 1998.

[5] J. Huang, A. Feria, M. Lou, The Development of Inflatable Array Antennas. IEEE Aerospace Conference, Big Sky, Montana, March 2000.

[6] J. Huang, A. Feria, A 1-m X-band Inflatable Reflectarray Antenna. Microwave and Optical Technology Letters, Vol. 20, No. 2, January 1999, pp. 97-99.

[7] J. Huang, R. J. Pogorzelski, Beam Scanning Reflectarray Antenna with Circular Polarization. U.S. Patent 6,081,234, June 2000.

Razvoj antenskih nizova na napuhavanje. Antenski su nizovi na napuhavanje razvijeni da bi se značajno smanjila masa, zapremina skladišnog prostora i cijena budućih svemirskih letjelica. Tri su nova antenska sustava na napuhavanje razvijena za primjenu na svemirskim letjelicama: antenski niz izmjera $3,3 \mathrm{~m} \times 1,0 \mathrm{~m}$ za radar sa sintetičkom antenom (SAR) u području frekvencija L, refleksijski niz promjera $1 \mathrm{~m}$ u frekvencijskom području $\mathrm{X}$ za telekomunikacijske primjene i refleksijski niz promjera $3 \mathrm{~m}$ u frekvencijskom području Ka, također za telekomunikacijske primjene. Sve su tri antene slične po izvedbi. Sve se tri sastoje od cjevaste strukture koja se napuhava te podržava i napinje višeslojnu tanku zračeću površinu s mikrotrakastim antenama. Ove su antene pokazale da su antenski nizovi na napuhavanje primjenjivi u cijelom mikrovalnom i milimetarskom valnom području. Smatra se da je potrebno daljnje unapređenje ovih antena posebno u području prilagodbe primjeni u svemirskim uvjetima.

Ključne riječi: antene, strukture na napuhavanje, planarni nizovi, refleksijski nizovi, svemirska letjelica

AUTHORS ADDRESS:

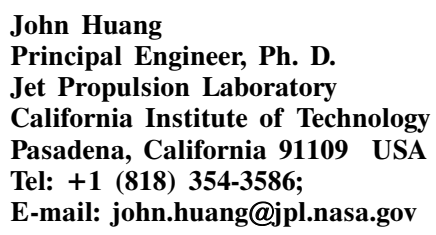

